Journal of Patient-Centered

\title{
Using Clinical Decision Support Within the Electronic Health Record to Reduce Incorrect Prescribing for Acute Sinusitis
}

\author{
Regina Ginzburg \\ Justin J. Conway \\ Eve Waltermaurer \\ Wendy Song \\ Samantha P. Jellinek-Cohen
}

Follow this and additional works at: https://aah.org/jpcrr

Part of the Bacterial Infections and Mycoses Commons, Health Information Technology Commons, Infectious Disease Commons, Primary Care Commons, Public Health Education and Promotion Commons, Virus Diseases Commons, and the Viruses Commons

\section{Recommended Citation}

Ginzburg R, Conway JJ, Waltermaurer E, Song W, Jellinek-Cohen SP. Using clinical decision support within the electronic health record to reduce incorrect prescribing for acute sinusitis. J Patient Cent Res Rev.

2018;5:196-203. doi: 10.17294/2330-0698.1619

Published quarterly by Midwest-based health system Advocate Aurora Health and indexed in PubMed Central, the Journal of Patient-Centered Research and Reviews (JPCRR) is an open access, peer-reviewed medical journal focused on disseminating scholarly works devoted to improving patient-centered care practices, health outcomes, and the patient experience. 


\title{
Using Clinical Decision Support Within the Electronic Health Record to Reduce Incorrect Prescribing for Acute Sinusitis
}

\author{
Regina Ginzburg, PharmD, ${ }^{1,2}$ Justin J. Conway, MD, ${ }^{3}$ Eve Waltermaurer, $\mathrm{PhD},{ }^{2}$ Wendy Song, $\mathrm{DO},{ }^{4}$ \\ Samantha P. Jellinek-Cohen, PharmD ${ }^{1,5}$ \\ ${ }^{1}$ St. John's University, Queens, NY; ${ }^{2}$ Institute for Family Health, New York, NY; ${ }^{3}$ Crystal Run Healthcare, Newburgh, NY; \\ ${ }^{4}$ Banner Health, Phoenix, AZ; ${ }^{5}$ Mount Sinai Beth Israel, New York, NY
}

Purpose $\quad$ Acute sinusitis has viral etiology in more than $90 \%$ of cases, but antibiotics are prescribed for more than $80 \%$ of adults in the United States. While applications of computer-assisted guidelines have been found effective in reducing inaccurate prescribing for acute respiratory infections, there is a paucity of research focused specifically on the utilization of electronic best practice alerts (BPA) in improving treatment for acute sinusitis.

Methods This observational cohort study examined prescribing behavior for sinusitis at a single Federally Qualified Health Center 1 year prior and during the first year of implementation of a BPA in the electronic health record (EHR) reminding providers of the recommended treatment of sinusitis. The advisory included a link to national guidelines and a note template was installed to assist providers in documentation. The BPA appeared on the providers' screen when an ICD-9 code of acute or bacterial sinusitis was entered during the patient visit.

Results After adjusting for select patient and provider factors, the computer-assisted guidelines effectively reduced the overall antibiotic prescribing among these patients by $31 \%$ (relative risk: $0.69,95 \%$ confidence interval: $0.51-0.95)$ and reduced incorrect prescribing from $88.5 \%$ to $78.7 \%(P=0.02)$.

Conclusions Clinical reminders within the EHR can be an effective tool to reduce inappropriate antibiotic use and improve providers' decisions regarding the correct antibiotic choices for patients with acute sinusitis. (J Patient Cent Res Rev. 2018;5:196-203.)

Keywords sinusitis; electronic health records; decision support; antibiotic prescribing; best practice alert

$\mathrm{A}$ cute sinusitis, also referred to as rhinosinusitis, is defined as inflammation of the paranasal sinuses and nasal cavity lasting less than 4 weeks. ${ }^{1,2}$ Approximately $12 \%$ of the adult population in the United States is diagnosed with acute sinusitis annually, accounting for roughly $20 \%$ of all antibiotic prescriptions per year for adults in the primary care setting. ${ }^{3,4}$ Bacterial sinusitis, however, only occurs in approximately $2 \%-10 \%$ of cases and usually results from a secondary infection 7-10 days after the initial

Correspondence: Regina Ginzburg, PharmD,

St. John's University, 8000 Utopia Parkway, St. Albert Hall, Room 114, Queens, NY 11439 (ginzburr@stjohns.edu) viral infection has manifested. ${ }^{1}$ Despite viral infections causing more than $90 \%$ of cases, a 2006 review of U.S. outpatient encounters found that antibiotics were prescribed for $81 \%$ of adults diagnosed with acute sinusitis. ${ }^{5}$ This data indicates that in the majority of cases antibiotics are being used inappropriately to treat viral sinusitis.

A recent Cochrane review examined randomized controlled trials comparing antibiotics with placebo or antibiotics from different classes for acute maxillary sinusitis in adults. The authors found that $80 \%$ of participants not treated with antibiotics improved within 2 weeks. ${ }^{4}$ The investigators therefore argued that clinicians must carefully balance the limited benefit 
of antibiotic against potential adverse effects. Adverse effects of antibiotics include but are not limited to rash, diarrhea, and Clostridium difficile infection. In addition, inappropriate antibiotic use can increase the risk of antibiotic resistance. ${ }^{6}$ In an effort to help guide primary care clinicians to decrease inappropriate antibiotic prescribing habits, the Infectious Disease Society of America (IDSA) released clinical practice guidelines in 2012 for the diagnosis and treatment of acute bacterial rhinosinusitis in children and adults. ${ }^{7}$

Given the high prevalence of sinusitis, coupled with the comparative complexity of antibiotic prescribing guidelines, several studies have examined variability in prescribing behaviors, typically comparing health care deliver type. ${ }^{8-10}$ These studies found variability between primary care, urgent care, and emergency department care on the use of antibiotics for acute sinusitis. ${ }^{10}$ In addition, variability based on provider specialty, presence of a medical trainee, and symptom duration each significantly influenced antibiotic prescribing. ${ }^{9}$

Previous studies in the literature report significant reductions in inappropriate antibiotic prescriptions using various interventions. Such interventions included informational patient handouts, peer-to-peer comparison, and mandatory written justification for antibiotic prescribing within the medical record. ${ }^{11,12}$ However, most of these studies center on antibiotic prescribing for health conditions for which antibiotics are not recommended (ie, influenza or upper respiratory infection). Sinusitis presents a unique challenge as the antibiotic prescribed may be appropriate in those who present with certain symptoms.

An older study looking at a computer-assisted management program for antibiotics found improved quality of care and reduced costs within that clinical site. ${ }^{13}$ Hillestad and colleagues also identified a benefit of electronic health records (EHR) in reducing both adverse effects and costs. ${ }^{14}$ More recently, various interventions involving clinical decision support within the EHR have been studied, though the majority of these interventions required physician training time outside of clinic hours and resulted in modest to insignificant reductions in antibiotic prescribing rates. ${ }^{15-19}$ Additionally, these findings focused primarily on acute respiratory infection protocols that were less complicated than that for sinusitis.
While there is little debate regarding the importance of accurate antibiotic prescribing, complexity of treatment for sinusitis, and efficacy of computerassisted management of medication, published research integrating these three elements remains sparse. Additionally, empirical examinations of the impact of provider- and patient-level factors on how these three elements most effectively work together are limited. Therefore, this study seeks to understand whether incorporation of a sinusitis-centric computer-assisted alert on the appropriate management of antibiotics in sinusitis can reduce overall prescribing, influence more accurate prescribing, and balance any differential prescribing by provider or patient characteristics.

\section{METHODS}

This was an observational cohort study conducted from May 2013 to May 2015 in an urban federally qualified health center and family medicine residency training site in New York City. The clinic provides full spectrum primary care to an ethnically and socioeconomically diverse population, with urgent care and scheduled primary care visits 7 days a week. Approximately 60,000 patient visits are seen annually within the clinic, with roughly one-quarter of the patients either having no insurance or on a government-subsidized plan. Medical providers included 27 family medicine residents, 25 full- and part-time attending physicians of varying years of experience, and 2 nurse practitioners of less than 5 years of experience. These medical providers work with multidisciplinary teams made up of social workers, psychiatrists, psychologists, a pharmacist, a certified diabetes educator, and ancillary staff.

\section{Intervention}

All patient encounters were documented using an EHR with the capability of including clinical decision support tools to aid the provider, which can be customized by the health care practice for a variety of different medical situations. One common decision tool utilized within the system is a best practice alert (BPA), which is a notification that informs the provider of evidence-based recommendations related to what is being prescribed. One specific BPA was created by our institution's Pharmacy and Therapeutics Committee related to acute sinusitis. This message stated that acute sinusitis is caused by a virus in more than $90 \%$ of cases. The BPA also contained a link to the 2012 IDSA acute bacterial sinusitis guidelines ${ }^{7}$ as 
well as a note template to assist providers in diagnosis of acute sinusitis at the point of care (Figure 1).

At our institution, clinicians must enter an associated diagnosis in order to prescribe an antibiotic in the EHR. The BPA was programmed to appear on the provider's computer screen at the time when the clinician entered an ICD-9 code corresponding to the diagnosis of acute sinusitis or bacterial sinusitis of the patient being seen. After a 6-month process of BPA design, testing, and editing, the final approval was given by the clinic's chief medical information officer, and the BPA was activated on May 13, 2014.

\section{Sample}

Data was collected via a report generated in the EHR identifying all patients who had an office visit in which a sinusitis diagnosis was entered in the 12 months before BPA implementation (May 14, 2013 - May 13, 2014) and 12 months after BPA implementation (May 14, 2014 - May 13, 2015). Patients were excluded if they were under the age of 18 years, were diagnosed with chronic sinusitis, presented for a refill of a nasal steroid spray, or were already taking antibiotics prescribed by another provider. Non-office visits (eg, telephone encounters) and visits in which the BPA was triggered but no sinusitis diagnosis was present in the final progress note also were excluded.

\section{Measures}

We examined a dichotomous measure of antibiotic prescribing (yes/no) to assess change in antibiotic prescribing incidence, as correct antibiotic prescribing is consistent with the purpose of this study. Correct antibiotics for bacterial sinusitis was defined using the 2012 IDSA recommendations of amoxicillin/ clavulanic acid $500 \mathrm{mg} / 125 \mathrm{mg}$ orally three times daily or $875 \mathrm{mg} / 125 \mathrm{mg}$ orally twice daily. For $\beta$-lactam allergic patients, the recommended alternatives were doxycycline $100 \mathrm{mg}$ orally twice daily or $200 \mathrm{mg}$ orally daily, levofloxacin $500 \mathrm{mg}$ orally daily, or moxifloxacin $400 \mathrm{mg}$ orally daily. Any of these recommended courses of therapies were to have a duration of 5 to 7 days. In addition, we examined a dichotomous measure of antibiotic prescribing (yes/no) to assess change in antibiotic prescribing incidence. Provider type, patient sociodemographic measures, and the presence of antibiotic allergies also were evaluated.

Most of the data was collected via the EHR-generated report. However, manual chart review was necessary to correlate symptom type and length. If symptoms

\section{$1>90 \%$ of Acute Sinusitis is caused by VIRUSES - not treated with antibiotics. If you think this might be a bacterial infection please use the attached criteria to evaluate. \\ Acknowledge reason: \\ Acknowledge \\ 『 Open SmartSet. evaluate SINUSITIS BACTERIAL CRITERIA before prescribing an antibiotic - most ( $>90$ percent) of Acute Sinusitis are VIRAL preview \\ 5 For bacterial treatment guidelines see IDSA Treatment Guidelines}

Acute Bacterial Sinusitis - meets one of the following:

1) Patient reports onset with PERSISTENT symptoms or signs compatible with acute rhinosinusitis, lasting for $>0$ r $=10$ days without any evidence of clinical improvement \{YES/NO:12275\}

2) Patient reports onset with SEVERE symptoms or signs of high fever $\left(>0 r=39^{\circ} \mathrm{C} / 102^{\circ} \mathrm{F}\right)$ and purulent nasal discharge or facial pain lasting for at least 3-4 consecutive days at the beginning of illness \{YES/NO:12275\}

3) Patient reports onset with WORSENING symptoms or signs characterized by the new onset of fever, headache or increase in nasal discharge following a typical viral URI that lasted 5-6 days and were initially improving ("double-sickening") \{YES/NO:12275\}

From IDSA Treatment Guidelines: http://www.idsociety.org/2012_Rhinosinusitis_Guidelines/

Figure 1. Electronic health record sinusitis best practice alert. 
were less than that duration recommended by IDSA for antibiotics and patient was given an antibiotic, it was deemed to be an inappropriate antibiotic prescription.

\section{Analyses}

Statistical analyses were performed using IBM SPSS Statistics for Windows, Version 24.0 (IBM Corp., Armonk, NY). Chi-squared tests were used to analyze categorical variables. Predictive models testing the likelihood of any antibiotic prescribing and correct antibiotic prescribing among patients with sinusitis were tested using a log-binomial regression to create relative and absolute risks.

\section{RESULTS}

During the 2-year study period, there were 438 cases of sinusitis presented at the primary health care clinic. More cases of sinusitis occurred in the postintervention year (Table 1). Most patients presenting with sinusitis

Table 1. Patient and Provider Descriptives Before and After BPA Implementation

\begin{tabular}{|c|c|c|c|c|}
\hline Descriptor & $\begin{array}{c}\text { Total cohort } \\
(\mathrm{N}=438), \mathrm{n}(\%)\end{array}$ & 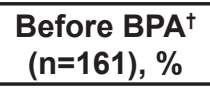 & $\begin{array}{l}\text { After BPA }{ }^{\dagger} \\
(\mathrm{n}=277), \%\end{array}$ & $P$ \\
\hline Age in years & & & & 0.16 \\
\hline Under 30 & $98(22.4)$ & 27.3 & 19.5 & \\
\hline $30-49$ & $199(45.4)$ & 42.9 & 46.9 & \\
\hline $50+$ & $141(32.2)$ & 29.8 & 33.6 & \\
\hline Race/ethnicity & & & & 0.12 \\
\hline White & $74(16.9)$ & 14.3 & 18.4 & \\
\hline Black & $46(10.5)$ & 12.4 & 9.4 & \\
\hline Hispanic & $56(12.8)$ & 10.6 & 14.1 & \\
\hline Other/multiple & $95(21.7)$ & 18 & 23.8 & \\
\hline Unknown & $167(38.1)$ & 44.7 & 32.3 & \\
\hline Gender & & & & 0.42 \\
\hline Male & $118(27.0)$ & 29.2 & 25.6 & \\
\hline Female & $320(73.0)$ & 70.8 & 74.4 & \\
\hline Allergy & & & & 0.04 \\
\hline None & $324(74.1)$ & 70.8 & 76.1 & \\
\hline PCN/Ceph & $69(15.8)$ & 14.3 & 16.7 & \\
\hline Other/multiple & $44(10.1)$ & 14.9 & 7.2 & \\
\hline Provider & & & & $<0.01$ \\
\hline Resident & $110(25.1)$ & 24.5 & 25.3 & \\
\hline Attending MD/DO & $203(46.3)$ & 34.8 & 53.1 & \\
\hline Nurse practitioner & $125(28.5)$ & 40.4 & 21.7 & \\
\hline Antibiotic prescribed? & & & & $<0.01$ \\
\hline No & $128(29.2)$ & 13.7 & 38.3 & \\
\hline Yes & $310(70.8)$ & 86.3 & 61.7 & \\
\hline Antibiotic prescribed correctly?* & & & & 0.02 \\
\hline No & $256(83.1)$ & 88.5 & 78.7 & \\
\hline Yes & $52(16.9)$ & 11.5 & 21.3 & \\
\hline
\end{tabular}

*Among patients who were prescribed.

${ }^{+}$Before BPA = May 14, 2013 - May 13, 2014; After BPA = May 14, 2014 - May 13, 2015.

BPA, best practice alert; DO, doctor of osteopathy; MD, medical doctor; PCN/Ceph, penicillins and cephalosporins. 
during the study period were female, were 30 to 49 years of age, and reported "unknown" race/ethnicity or none at all. Nearly three-quarters of patients reported not having a medication allergy. While there were no demographic differences between patients seen during the time period preceding the sinusitis-related prescribing BPA compared with the year after implementation, there was a significantly lower proportion of patients reporting some medication allergy during the baseline period. In addition, patients were seen by fewer nurse practitioners and more medical doctors or doctors of osteopathy after the BPA implementation.

Overall, prescribing of antibiotics significantly declined after the BPA implementation from $86.3 \%$ to $61.7 \%$ $(\mathrm{P}<0.01)$. When adjusting for measured covariates, the prediction model for antibiotic prescribing after BPA implementation showed a $31 \%$ reduction in overall antibiotic prescribing (relative risk [RR]: 0.69, 95\% confidence interval [CI]: 0.51-0.95).

Incorrect prescribing also declined after BPA implementation from $88.5 \%$ to $78.7 \%(\mathrm{P}=0.02)$ for an absolute risk reduction of $9.8 \%$. In the prediction model for likelihood of correct prescribing after adjusting for measured covariates (Model 4), providers following the BPA were more than twice as likely to prescribe correctly after the BPA implementation (RR: 2.03, 95\% CI: 1.02-4.06). When antibiotics were prescribed, the most frequently used IDSA criteria to justify their use was duration of patient symptoms.

As a secondary analysis, measured covariates for predicting overall and correct prescribing also were examined. Models 1 and 2 (Table 2) revealed no patient or provider factors to predict overall prescribing. Alternatively, Model 3 identified that NPs and attending physicians were significantly less likely to correctly prescribe antibiotics for sinusitis compared with medical residents before (59\% and $72 \%$ less likely, respectively) and after $(53 \%$ and $75 \%)$ the BPA implementation (Table 3). Additionally, patient race/ethnicity classified as "Hispanic" resulted in a 3-4 times increased likelihood of correct antibiotic prescribing compared with white patients before and after the BPA implementation. These data suggest that patient and provider factors influencing correct prescribing were not eliminated by the BPA implementation.

Table 2. Predictive Models for Overall Prescribing per Log-Binomial Regression

\begin{tabular}{|c|c|c|c|c|c|c|c|c|c|c|}
\hline \multirow[b]{2}{*}{ Antibiotic prescribing* } & \multicolumn{5}{|c|}{$\begin{array}{l}\text { Model 1: Any prescribing } \\
\text { intervention excluded }\end{array}$} & \multicolumn{5}{|c|}{$\begin{array}{l}\text { Model 2: Any prescribing } \\
\text { intervention included }\end{array}$} \\
\hline & $\mathrm{B}$ & SE & $P$ & $\mathbf{R R}$ & $95 \% \mathrm{Cl}$ & $\mathbf{B}$ & SE & $P$ & $\mathbf{R R}$ & $95 \% \mathrm{Cl}$ \\
\hline Time period (baseline control) & - & - & - & - & - & -0.36 & $(0.16)$ & 0.02 & 0.69 & $(0.51-0.95)$ \\
\hline Provider NP (resident control) & 0.09 & $(0.21)$ & 0.68 & 1.09 & $(0.73-1.64)$ & 0.02 & $(0.21)$ & 0.94 & 1.02 & $(0.67-1.54)$ \\
\hline Provider MD/DO (resident control) & 0.09 & $(0.19)$ & 0.62 & 1.10 & $(0.76-1.59)$ & 0.14 & $(0.19)$ & 0.47 & 1.15 & $(0.79-1.66)$ \\
\hline Allergy PCN/Ceph (none control) & 0.19 & $(0.24)$ & 0.45 & 1.20 & $(0.75-1.94)$ & 0.11 & $(0.25)$ & 0.64 & 1.12 & $(0.69-1.82)$ \\
\hline Allergy other (none control) & 0.16 & $(0.21)$ & 0.43 & 1.18 & $(0.78-1.77)$ & 0.18 & $(0.21)$ & 0.39 & 1.20 & $(0.80-1.81)$ \\
\hline Gender (male control) & -0.04 & $(0.17)$ & 0.80 & 0.96 & $(0.69-1.34)$ & -0.04 & $(0.17)$ & 0.83 & 0.96 & $(0.69-1.35)$ \\
\hline Age $50+$ years (under 30 control) & -0.03 & $(0.21)$ & 0.89 & 0.97 & $(0.65-1.46)$ & 0.03 & $(0.21)$ & 0.89 & 1.03 & $(0.68-1.54)$ \\
\hline Age $30-49$ years (under 30 control) & -0.09 & $(0.20)$ & 0.66 & 0.92 & $(0.63-1.34)$ & -0.05 & $(0.20)$ & 0.80 & 0.95 & $(0.65-1.40)$ \\
\hline Race/ethnicity unknown (white control) & 0.01 & $(0.22)$ & 0.97 & 1.01 & $(0.66-1.55)$ & -0.04 & $(0.22)$ & 0.87 & 0.97 & $(0.63-1.49)$ \\
\hline Race/ethnicity black (white control) & -0.13 & $(0.30)$ & 0.67 & 0.88 & $(0.49-1.59)$ & -0.19 & $(0.30)$ & 0.52 & 0.82 & $(0.46-1.49)$ \\
\hline Race/ethnicity Hispanic (white control) & -0.09 & $(0.28)$ & 0.74 & 0.91 & $(0.52-1.59)$ & -0.09 & $(0.29)$ & 0.75 & 0.91 & $(0.52-1.60)$ \\
\hline Race/ethnicity other (white control) & -0.07 & $(0.24)$ & 0.78 & 0.93 & $(0.58-1.51)$ & -0.06 & $(0.25)$ & 0.80 & 0.94 & $(0.58-1.52)$ \\
\hline
\end{tabular}

*1 = prescribed.

$B$, binomial estimate; $C l$, confidence interval; DO, doctor of osteopathy; $M D$, medical doctor; NP, nurse practitioner; PCN/Ceph, penicillins or cephalosporins; RR, relative risk; SE, standard error. 
Table 3. Predictive Models for Correct Prescribing per Log-Binomial Regression

\begin{tabular}{l|ccccc|ccccc}
\hline & \multicolumn{4}{|c|}{$\begin{array}{c}\text { Model 3: Correct prescribing } \\
\text { intervention excluded }\end{array}$} & \multicolumn{4}{c}{$\begin{array}{c}\text { Model 4: Correct prescribing } \\
\text { intervention included }\end{array}$} \\
\cline { 2 - 11 } Correct antibiotic prescribing* & B & SE & $\boldsymbol{P}$ & $\mathbf{R R}$ & $\mathbf{9 5 \%}$ Cl & B & SE & $\boldsymbol{P}$ & RR & $\mathbf{9 5 \% ~ C l}$ \\
\hline Time period (baseline control) & - & - & - & - & - & 0.71 & $(0.35)$ & 0.04 & 2.03 & $(1.02-4.06)$ \\
Provider NP (resident control) & -0.88 & $(0.39)$ & 0.03 & 0.41 & $(0.19-0.90)$ & -0.76 & $(0.40)$ & 0.06 & 0.47 & $(0.21-1.02)$ \\
Provider MD/DO (resident control) & -1.28 & $(0.38)$ & $<0.01$ & 0.28 & $(0.13-0.59)$ & -1.38 & $(0.38)$ & $<0.01$ & 0.25 & $(0.12-0.54)$ \\
Allergy PCN/Ceph (none control) & 0.07 & $(0.53)$ & 0.89 & 1.08 & $(0.38-3.07)$ & 0.18 & $(0.54)$ & 0.74 & 1.20 & $(0.42-3.46)$ \\
Allergy other (none control) & 0.42 & $(0.38)$ & 0.27 & 1.52 & $(0.72-3.19)$ & 0.33 & $(0.38)$ & 0.39 & 1.40 & $(0.66-2.96)$ \\
Gender (male control) & -0.03 & $(0.35)$ & 0.92 & 0.97 & $(0.48-1.93)$ & -0.02 & $(0.35)$ & 0.95 & 0.98 & $(0.49-1.96)$ \\
Age 50+ years (under 30 control) & -0.34 & $(0.43)$ & 0.43 & 0.72 & $(0.31-1.66)$ & -0.46 & $(0.44)$ & 0.29 & 0.63 & $(0.27-1.48)$ \\
Age 30-49 years (under 30 control) & -0.24 & $(0.40)$ & 0.54 & 0.78 & $(0.36-1.71)$ & -0.31 & $(0.40)$ & 0.44 & 0.73 & $(0.33-1.62)$ \\
Race/ethnicity unknown (white control) & 1.12 & $(0.58)$ & 0.05 & 3.07 & $(0.98-9.60)$ & 1.19 & $(0.59)$ & 0.04 & 3.29 & $(1.04-10.35)$ \\
Race/ethnicity black (white control) & 0.13 & $(0.91)$ & 0.88 & 1.14 & $(0.19-6.81)$ & 0.30 & $(0.92)$ & 0.75 & 1.35 & $(0.22-8.15)$ \\
Race/ethnicity Hispanic (white control) & 1.35 & $(0.67)$ & 0.04 & 3.84 & $(1.04-14.19)$ & 1.33 & $(0.67)$ & 0.05 & 3.76 & $(1.02-13.96)$ \\
Race/ethnicity other (white control) & 1.04 & $(0.62)$ & 0.10 & 2.82 & $(0.83-9.53)$ & 0.99 & $(0.62)$ & 0.11 & 2.70 & $(0.80-9.14)$ \\
\hline
\end{tabular}

*1 = correct.

$B$, binomial estimate; $C l$, confidence interval; $D O$, doctor of osteopathy; $M D$, medical doctor; $N P$, nurse practitioner; $P C N / C e p h$, penicillins or cephalosporins; $R R$, relative risk; SE, standard error.

\section{DISCUSSION}

Data collected prior to BPA implementation demonstrated that the clinic's rate of antibiotic prescribing for acute sinusitis (86.3\%) was similar to national averages. This rate is a sharp contrast to the $\leq 10 \%$ overall incidence of bacterial etiology of acute sinusitis. After our intervention, the antibiotic prescribing rates decreased to $61.7 \%$, which is considerably lower than national averages.

In this study, provider type played a role in accurate prescribing; residents were more likely to prescribe accurately compared to attending physicians and nurse practitioners. These results are consistent with previously published data. Roumie et al conducted a cross-sectional study of adult patients treated by practicing physicians, nonphysician clinicians (physician assistants and nurse practitioners), and residents in emergency departments, office, and hospital practices. ${ }^{20}$ Antibiotic prescribing patterns were compared among respiratory diagnoses for which antibiotics are rarely indicated but for which an antibiotic was prescribed. Nonphysician clinicians prescribed antibiotics more often than practicing physicians in office practices (odds ratio [OR]: 1.86,
95\% CI: 1.05-3.29) and hospital practices (OR: 1.55, 95\% CI: 1.12-2.15). In hospital practices, residents had lower prescribing rates than practicing physicians (OR: 0.56, 95\% CI: 0.36-0.86).

This study also explored overall antibiotic prescribing for sinusitis presentations. No patient or provider factor was found to predict that an antibiotic would be prescribed. When adjusting for patient and provider factors, the implementation of a prescribing BPA reduced overall prescribing by $31 \%$. These results are comparable with other published reports. Linder et al found a $5 \%$ reduction in visits with antibiotic prescribing after implementation of a clinical decision support for progress notes, though this was for all acute respiratory tract infections. ${ }^{17}$ Similarly, Davis et al reported a $24 \%$ decrease in antibiotic prescribing in acute otitis media with the introduction of a real-time EHR alert on evidenced-based prescribing. ${ }^{21}$ Other reported interventions typically required an outside intervention or training beyond the point of care. ${ }^{15-19}$

This study examined the impact of a computerassisted management tool on improving antibiotic prescribing for patients presenting with acute sinusitis 
at the point of care. The implementation of a BPA with decision-making guidance from the 2012 IDSA sinusitis guidelines independently improved accurate prescribing by over $100 \%$. This supports other studies where the impact of a computer-assisted clinical management tool improved antibiotic prescribing. ${ }^{15,16}$

In this study, some racial disparity was noted in our subgroup analysis wherein white patients were more likely to have an antibiotic ordered incorrectly compared to Hispanic status before and after the implementation. Currently, there are very limited published studies describing racial differences in antibiotic prescribing for upper respiratory infections. Two retrospective cohort studies also reported white patients to receive more antibiotics compared to black and Hispanic; however, these analyses only included children. ${ }^{22,23}$ To date, our study is the only available report that identified racial differences in antibiotic prescribing for sinusitis in adults. Further investigation in this area is warranted.

\section{Limitations}

One limitation of our study is that it was performed at a single clinic site, which resulted in a smaller sample size when compared with multicentered studies. A larger sample may have allowed greater precision in the models assessing overall prescribing to identify influence of any significant provider or patient factors. Additionally, the intervention was implemented within a family medicine residency teaching program that may not be generalizable to other primary care settings. However, the diverse patient population served by the clinic, the large number of annual visits, and the inclusion of both residents, attending physicians, and nurse practitioners represent a broad spectrum of both patients and providers that may make the findings applicable to other sites.

It also may be possible that those who actually sought medical care may have had a more severe disease course, making them more likely to have a bacterial versus viral sinus infection, which may have led the physician to prescribe the antibiotic. However, the IDSA lists specification for the type and duration of symptoms needed before an antibiotic is prescribed. Those who met these criteria were classified as being prescribed an antibiotic appropriately. Lack of adequate documentation of these symptoms by the provider in the EHR may have been possible. The BPA was built with the option to use the preset acute sinusitis note so that adequate documentation could be incorporated into the progress note. However, the effectiveness of the BPA may be limited by "alert fatigue," causing some providers to ignore the clinical decision support tool. ${ }^{24}$

Lastly, we are unsure why a greater number of our patients were diagnosed with sinusitis in year 2. It seems unlikely that this result was due to the BPA, which fired only after the diagnosis was entered. That said, given the increase, the improvement in correct prescribing is even more significant.

\section{CONCLUSIONS}

Clinical decision support within the electronic health record at the point of care can be an effective tool to decrease inappropriate antibiotic use and improve providers' decisions regarding correct antibiotic choices when treatment with antibiotics is deemed suitable. The growing problem of antibiotic resistance in health care makes this finding of particular importance and necessitates further study in EHRbased interventions to reduce overprescribing of antibiotics.

\section{Patient-Friendly Recap}

- Acute sinusitis, a common infection in adults, is nearly always viral in nature and resolves on its own after a few weeks.

- Despite the unlikelihood a given case is caused by bacteria, antibiotics are very frequently prescribed to these patients, resulting in unwarranted exposure.

- The authors embedded an alert in the electronic health record to educate providers about the preferred course of treatment for acute sinusitis.

- This "best practice alert" effectively reduced improper prescribing of antibiotics. Widespread application may help address the important problem of antibiotic resistance in the general population. 


\section{Author Contributions}

Study design: Conway, Song, Ginzburg. Data acquisition or analysis: all authors. Manuscript drafting: Conway, Song, Ginzburg. Critical revision: Waltermaurer, Jellinek-Cohen.

\section{Conflicts of Interest}

None.

\section{References}

1. Snow V, Mottur-Pilson C, Hickner JM, et al. Principles of appropriate antibiotic use for acute sinusitis in adults. Ann Intern Med. 2001;134:495-7. CrossRef

2. Patel ZM, Hwang PH. Acute sinusitis and rhinosinusitis in adults: clinical manifestations and diagnosis. UpToDate ${ }^{\circledR} .2018$ Feb 15. https://www.uptodate.com/contents/acute-sinusitis-andrhinosinusitis-in-adults-clinical-manifestations-anddiagnosis? search=uncomplicated-acute-sinusitis-andrhinosinusitis-in-adults\&source $=$ search_result\&selected Title $=2 \sim 150 \&$ usage_type $=$ default\&display_rank $=2$. Accessed February 2, 2016.

3. Blackwell D1, Lucas JW, Clarke TC. Summary health statistics for U.S. adults: National Health Interview Survey, 2012. Vital Health Stat 10. 2014;(260):1-161.

4. Ahovuo-Saloranta A, Rautakorpi UM, Borisenko OV, Liira H, Williams JW Jr, Mäkelä M. Antibiotics for acute maxillary sinusitis in adults. Cochrane Database Syst Rev. 2014;(2):CD000243. CrossRef

5. Gill JM, Fleischut P, Haas S, Pellini B, Crawford A, Nash DB. Use of antibiotics for adult upper respiratory infections in outpatient settings: a national ambulatory network study. Fam Med. 2006;38:349-54.

6. Review on Antimicrobial Resistance. Antimicrobial Resistance: Tackling a Crisis for the Future Health and Wealth of Nations. Published December 2014. https:// amr-review.org/sites/default/files/AMR\%20Review\%20 Paper\%20-\%20Tackling\%20a\%20crisis\%20for\%20 the $\% 20$ health $\% 20$ and $\% 20$ wealth $\% 20$ of $\% 20$ nations_1.pdf. Accessed February 2016.

7. Chow AW, Benninger MS, Brook I, et al. IDSA clinical practice guideline for acute bacterial rhinosinusitis in children and adults. Clin Infect Dis. 2012;54:e72-e112. CrossRef

8. Smith SS, Kern RC, Chandra RK, Tan BK, Evans CT. Variations in antibiotic prescribing of acute rhinosinusitis in United States ambulatory settings. Otolaryngol Head Neck Surg. 2013;148:852-9. CrossRef

9. Pynnonen MA, Lynn S, Kern HE, et al. Diagnosis and treatment of acute sinusitis in the primary care setting: a retrospective cohort. Laryngoscope. 2015;125:2266-72. CrossRef

10. Sharp AL, Klau M, Keschner D, et al. Assessing current practices in the evaluation and treatment of acute sinusitis: a comparison of primary care, urgent care and emergency department care. (abstr.) J Patient Cent Res Rev. 2015;2:136. CrossRef
11. de Bont EG, Alink M, Falkenberg FC, Dinant GJ, Cals JW. Patient information leaflets to reduce antibiotic use and reconsultation rates in general practice: a systematic review. BMJ Open. 2015;5(6):e007612. CrossRef

12. Meeker D, Linder JA, Fox CR, et al. Effect of behavioral interventions on inappropriate antibiotic prescribing among primary care practices: a randomized clinical trial. JAMA. 2016;315:562-70. CrossRef

13. Evans RS, Pestotnik SL, Classen DC, et al. A computer-assisted management program for antibiotics and other antiinfective agents. N Engl J Med. 1998;338:232-8. CrossRef

14. Hillestad R, Bigelow J, Bower A, et al. Can electronic medical record systems transform health care? Potential health benefits, savings, and costs. Health Aff (Millwood). 2005;24:1103-17. CrossRef

15. Litvin CB, Ornstein SM, Wessell AM, Nemeth LS, Nietert PJ. Use of an electronic health record clinical decision support tool to improve antibiotic prescribing for acute respiratory infections: the ABX-TRIP study. $J$ Gen Intern Med. 2013;28:810-6. CrossRef

16. Mainous AG 3rd, Lambourne CA, Nietert PJ. Impact of a clinical decision support system on antibiotic prescribing for acute respiratory infections in primary care: quasi-experimental trial. J Am Med Inform Assoc. 2013;20:317-24. CrossRef

17. Linder JA, Schnipper J, Tsurikova R, et al. Documentationbased clinical decision support to improve antibiotic prescribing for acute respiratory infections in primary care: a cluster randomised controlled trial. Inform Prim Care. 2009; 17:231-40. CrossRef

18. Linder JA, Schnipper JL, Tsurikova R, et al. Electronic health record feedback to improve antibiotic prescribing for acute respiratory infections. Am J Manag Care. 2010;16(12 Suppl HIT):e311-9.

19. Feldstein DA, Hess R, McGinn $\mathrm{T}$, et al. Design and implementation of electronic health record integrated clinical prediction rules (iCPR): a randomized trial in diverse primary care settings. Implement Sci. 2017;12(1):37. CrossRef

20. Roumie CL, Halasa NB, Edwards KM, Zhu Y, Dittus RS, Griffin MR. Differences in antibiotic prescribing among physicians, residents, and nonphysician clinicians. Am J Med. 2005;118:641-8. CrossRef

21. Davis RL, Wright J, Chalmers F, et al. A cluster randomized clinical trial to improve prescribing patterns in ambulatory pediatrics. PLoS Clin Trials. 2007;2(5):e25. CrossRef

22. Goyal MK, Johnson TJ, Chamberlain JM, et al. Racial and ethnic differences in antibiotic use for viral illness in emergency departments. Pediatrics. 2017;140(4):e20170203. CrossRef

23. Gerber JS, Prasad PA, Localio AR, et al. Racial differences in antibiotic prescribing by primary care pediatricians. Pediatrics. 2013;131(4):677-84. CrossRef

24. Nanji KC, Slight SP, Seger DL, et al. Overrides of medicationrelated clinical decision support alerts in outpatients. $J \mathrm{Am}$ Med Inform Assoc. 2014;21:487-91. CrossRef

(C) 2018 Aurora Health Care, Inc. 